\title{
Cytogenetical Studies on the Effects of Some Chlorinated Pesticides III. Concluding remarks
}

\author{
Ajay K. Jain and R. K. Sarbhoy ${ }^{1}$ \\ Laboratory of Mutagenesis, National Institute of Genetics, \\ Yata 1,111, Mishima 411, Japan
}

Accepted October 16, 1985

The use of pesticides is unavoidable in modern agriculture. Several million tons of organic and inorganic chemicals with antimicrobial and insecticidal properties are added annually in soil and their environment. Some of them while killing or inhibiting the harmful organisms not only upset the ecosystem but also produce undesirable changes in higher organisms. The present study was undertaken in order to assess the cytogenetic effects of some widely used chlorinated pesticides-Benzene hexachloride (BHC), Lindane, Aldrin, Heptachlor and Endrin on plant system.

\section{Meterial and methods}

The detailed methodology has been described in Part I and II (1987) of this series.

\section{Results and discussion}

\section{A) Effect on somatic chromosomes}

The immediate effect of all the pesticide treatment was partial or entire inactivation of spindle mechanism followed by scattering of chromosomes. Benzene hexachloride (BHC) has been observed to affect spindle apparatus more severely than Lindane, Aldrin, Heptachlor and Endrin. The spindle inactivation affected the chromosomes movement. The various theories which have been put forwarded to explain chromosomes movement during cell division does not seems to be entirely satisfactory. The various pesticides were differently potent in disturbing the spindle apparatus. No normal metaphase stage was observed after $2 \mathrm{hr}$. root-tip treatment of BHC, while in Lindane and Endrin treatment stages were observed in low magnitude (data not presented here). The normal metaphase stages were observed in higher percentage after Aldrin and Heptachlor treatment in compare to BHC, Lindane and Endrin treatments for the same duration of treatment (data not presented here). In Aldrin and Heptachlor treatments the concentrations used were ten times greater than BHC, Lindane and Endrin treatments. Therefore, alteration in viscosity of karyolymph will be greater in Aldrin and Heptachlor treated roottips than BHC, Lindane and Endrin treated. Hence, as per viscosity and hydration theory (Wassermann 1929), no normal cell would be observed in Aldrin and Heptachlor treated roottips; however, normal cells were observed in all the treatments.

The chromosome autonomy theory (Frey-Wyssling 1938) seems partially responsible for chromosome movement as the chromosomes possess energy in the form of adenosine triphosphate (ATP) necessary for their movement. Epel (1963) found complete inhibition of mitosis when ATP level dropped below the $50 \%$ of normal level. Hence, it may be presumed that the chemicals which affect ATP and sugar synthesis by creating annoxia condition or by other means exert much effect on chromosomes movement. The oxygen defficiency is known to

1 Department of Botany, Agra College, Agra (U.P.), India. 
cause delay in onset of division by arresting cells at metaphase (Gimenz and Lopez-saez 1962). Amoore $(1961 \mathrm{a}, \mathrm{b})$ reported that the cell division in pea roots depends upon the presence of oxygen and can be arrested by the lack of $\mathrm{O}_{2}$. The present study reveals that there was a tendency towards the arrest of division at metaphase or lengthen the period cycle of division as it is evident by the higher occurrence of metaphase than anaphase and telophase. Hoffman-Berling (1954) opined that the chromosomes move under the influence of ATP. Since ATP, sugar and protein metabolic pathways are interrelated, therefore alteration in sugar and protein synthesis may also affect chromosomes movement. D'Amato (1949) observed recovery tendency of chromosomes after the addition of sugars like m-inositol. Cummins et al. (1966) reported that the proteins which determine the duration of transition from metaphase to onwards are concerned with the transformation of chemical energy into the mechanical work of mitosis. This assumption is also strengthened by the fact that cell division is inhibited by agents which supress the energy generating processes i.e. glycolysis, respiration and oxidative phosphorylation. A few well known mitotic inhibitors are Azaserine-an antibiotic (Tanaka and Sugimura 1956), Aminopterin and Amethopterin (Hughes 1952)and 5 Fluorodeoxyuridine (Taylor 1962, Kihlman 1962). Bullought (1952) opined that energy required for mitosis is produced during a particular stage of the mitotic cycle-antephase. It has not been established that when antephase begins, but it onsets when prophase begins. According to Swann (1954), energy is steadily released by respiration and stored in the form of some organic compounds and is utilised in starting the division. Epel (1963) reported that the rate of mitosis was closely related to the resultant level of ATP and mitosis could be blocked at any stage at appropriate time by adding optimum concentration of respiratory inhibitors.

Hence, it may be concluded that the cell division is energy dependent process and thereby the movement of chromosomes mainly depends upon the energy generating system. The pesticide treatment somehow disturbed the respiratory pathways, resulting in the low accumulation of energy containing and other essential compounds-ATP, sugar and protein molecules etc.. The present sudy reveals that BHC caused more hinderance in chromosomes movement than other screened pesticides under the same conditions. In BHC root-tip treatments particularly all the cells were affected while in Lindane, Heptachlor, Aldrin and Endrin root-tip treatments some cells were not affected as it is evident by the presence of higher average mean percentage (A.M. \%) of normal metaphase stage-Lindane: L. esculenta 2.64 A.M. $\%$, P. arvense 3.30 A.M. $\%$, P. sativum 5.20 A.M. \%; Aldrin: L. esculenta 6.35 A.M. $\%$, L. culinaris 6.59 A.M. $\%$, P. sativum 7.89 A.M. $\%$, P. arvense 12.00 A.M. $\%$; Heptachlor: $L$. culinaris 2.60 A.M. $\%, L$. esculenta 3.35 A.M. $\%$, P. arvense 8.03 A.M. $\%$, P. sativum 8.12 A.M. $\%$; Endrin: P. arvense 2.94 A.M. \%, L. esculenta 3.61 A.M. \%, L. culinaris 5.70 A.M. \% (Part I-Table 1). It may be visualized that Lindane-the gamma isomer of $\mathrm{BHC}$ is not as potent cyto-disrupter as BHC. Hence, the cause of cyto-disrupter efficiency of BHC may not be attributed entirely to its gam$\mathrm{ma}$ isomer-Lindane. The disturbance in chromosomes movement may be due to combined action of other isomers also.

Hence, it seems that more than one factor in combination may be responsible for chromosomes movement. However, it stimulates for further investigations to find out the exact relationship between chromosomes movement and ATP, ATPase, sugars, proteins, RNA and DNA synthesis in order to achieve a definite conclusion.

From the present study it appears that the chromosomes of Pisum were less affected than Lens. The difference might be due to variation in chromosome size, resistance of plant and spindle stiffness. Sharma and Chatterjee (1962) reported that large chromosomes are more susceptible to chemical and radiation treatments. Edwards (1962) also found that Pisum is less sensitive test material than Allium to the treatment of Acenaphthene derivatives and attributed the cause to the fact that Pisum root is relatively impermeable. 
The presence of sticky chromosomes or condensation of chromosomes below their normal size at metaphase might also be due to delay in chromosomes movement by pesticides treatment. The size of chromosomes in different stages is controlled by gene(s). As a result of pesticide treatment the chromosomes could not reach to the poles and remain scattered in cytoplasm, so due to gene action the chromosomes took condensed and sticky appearance. However, Klasterska et al. (1976) and McGill et al. (1974) suggested that chromosomes stickiness arises due to improper folding of the chromosomes fiber into single chromatid and chromosome.

\section{Multipolar spindle and unequal separation of chromosomes}

The abnormality was observed only in BHC, Lindane and Endrin treatments. Multipolar spindle and unequal separation of chromosomes have also been reported due to some other pesticides: 2,4D 2,4-dichlorophenoxyacetic acid (Mohandas and Grant 1972), Diuran 3-(3,4dichlorophenyl)-1,1-dimethylurea (Tomkins and Grant 1976) Simazine 2-chloro-4,6-bis (ethyl amino) s-triazine (Tomkins and Grant 1976). A plausible explanation might be that the inactivation of spindle apparatus was so much pronounced that the chromosomes could not regain the normal position as happened in Aldrin and Heptachlor treatments. Kumar et al. (1978) reported that multipolar condition is determined by position and number of poles. The number of poles in a cell depends on the position of the assemblage of RNA and polysaccharides which remain distributed either in the form of sol or gel (Prasad 1974). This abnormality seems specific and is produced by certain chemicals not by all.

\section{Polyploid cells}

The C-mitotic activity of BHC and Lindane has also been reported by (Kostoff 1948a, b, D'Amato 1949, Sharma and Chaudhri 1959, Baquar and Khan 1971). From the present study it appears that Lindane (gamma isomer of $\mathrm{BHC}$ ) is not entirely responsible for C-mitotic activity of $\mathrm{BHC}$ and is less potent polyploidizing agent. Colchicine, the well known polyploidizing agent exists in two isomeric forms-colchicine and isocolchicine. Steinegger and Levan (1947) reported that isocolchicine was less effective than colchicine in inducing C-mitosis in $A$. cepa. Likewise, Lindane is less effective in inducing C-mitosis. Polyploid cells were totally absent in Aldrin, Heptachlor and Endrin treatments. This indicates that the induction of C-mitosis is a specific type of abnormality induced by certain chemicals possessing peculiar mode of action. A number of organochlorous pesticides have been reported to induce C-mitosis-Chloranil (Yakar 1952), DDT (Vaarama 1947), Pentachlorophenol (Sawamura 1965). Therefore, the term B-mitosis seems more appropriate in order to represent such mitosis particularly induced by pesticides.

In BHC and Lindane treatments the chromosomes failed to arrange themselves in equatorial plate due to non functioning of spindle and energy defficiency the division of centromeric region is delayed resulting in the accumulation of metaphase stages. During the division corresponding to anaphase (B-anaphase) the centromeres divide and the daughter chromosomes fall apart but owing to the defficiency of energy and definite poles the daughter chromosomes fail to assemble at definite poles. This results in the accumulation of tetraploid-vice versa than the normal number of chromosomes. At the begining of telophase (B-telophase) the chromosomes start contraction and forming euploid nucleus. However, all the chromosomes in one cell do not assemble at one place to form one nucleus but at different centres forming more than one euploid or aneuploid nuclei in one cell.

No definite mechanism can be assigned to the mode of action of polyploidizing agents. Levan and Östergren (1943) postulated that the C-mitotic activity of a compound is determined by its concentration in liquid phase of the cell. Östergren (1944) reported that C-mitotic agents act upon the lipophilic side chains of the spindle proteins and cause folding of the poly- 
peptide chains with a concomitant transition of fibrous spindle proteins into more globular forms which are incompatible with spindle structure and function. It seems that BHC and Lindane act more specifically by a physical mechanism because a slight change in BHC composition reduces its activity drastically. The probable mode of action may be that $\mathrm{BHC}$ and Lindane decompose or somehow give out Benzene which interferes in cell division and causes B-mitosis. Benzene vapours and liquid are already known to cause B-mitosis (Berger et al. 1944)

\section{Multinucleate cells}

The multinucleate cells were found in BHC treatment (Kostoff 1948a, b, Quidet and Hitier 1948, Sharma and Sharma 1961, Datta 1966). The probable mechanism seems that the development of cell plate is checked due to BHC treatments. The precise mechanism by which the cell plate is formed is not exactly known. Buvat (1963) and Whalley and Mollenhauer (1963) observed a series of vesicles in the equatorial zone which apparently are a product of the Golgi apparatus. The cell plate is formed by a fusion of these vesicles. Porter and Machado (1960) and Whalley et al. (1960) have shown that fragments of endoplasmic reticulum constitute the cell plate. Henceby, being obscure mechanism of cell plate development, no definite mode of action can be assigned to anti-cytokinetic activity of $\mathrm{BHC}$.

\section{B) Effect of meiotic chromosomes}

The most common abnormality induced by all pesticides was the stickiness of chromosomes. The abnormality was observed in greater magnitude due to spray treatment than seedsoak treatment. The stickiness was observed in high percentage at metaphase-I and in low percentage in later meiotic stages. This suggests either the abnormality has reverted back to normal in later stages of meiosis or such PMC's did not complete their meiotic cycle. Sparrow and Rossenfeld (1946) reported sticky metaphase stages shortly after X-irradiation. Amer and Ali (1968) emphasized that stickiness is a common effect induced by different chemicals and suggested that stickiness is a temporary effect. Darlington (1953) reported that stickiness arises from the depolymerisation of DNA on the surface of chromosomes. It seems that stickiness is a physiological rather than genic effect induced by various chemicals or physical agents in meiosis (Amer et al. 1969). The lagging chromosomes were observed at metaphase-I, anaphase-I and ana-telophase-II. However, the frequency of lagging chromosomes at anaphase-I and ana-telophase-II was low and was found in spray treatment of BHC, Lindane, Endrin and Heptachlor. Although they were not observed in all the four tested plants. Such abnormality was also observed in Vicia faba after spray and seed-soak treatments with 2,4,5-trichlorophenol and 2,4,5-trichlorophenoxyacetic acid (Amer and Ali 1974). It seems that the treatment produced hindrance in the movement and stickiness of the bivalents.

The fragments were observed in BHC, Lindane, Heptachlor and Endrin spray and seedsoak treatments. However, the fragments were not observed in $P$. arvense due to Heptachlor and Lindane seed-soak treatments. BHC, Lindane, Heptachlor and Endrin have also been found to affect fragmentation in somatic chromosomes but Aldrin was found to be effective in meiotic chromosomes. The fragments have also been reported by the treatments of various pesticides-BHC (Sharma and Talukdar 1965); o-nitrophenol, p-chlorophenol and pentachlorophenol (Amer and Ali 1968). The physical radiations are also known to cause fragmentation$\beta$-rays (Kobayashi 1958), X-rays (Kobayashi 1958). Hence, the mechanism responsible for chromosome breaks with pesticides seems more or less similar to that has been reported for Xrays and other chemical mutagens. Since enzymes are known to play a maior role in maintainingthe numerous biochemical processes, the application of pesticides may inhibit or enhance the synthesis of certain enzymes i.e. disturb the cell system resulting in the union or separation of homologous and non-homologous chromosomes leading to exchange of chromosome 
parts. In some cases the exchanged parts do not remain attached with the chromosome and are found in cytoplasm in the form of fragments. Sharma and Sharma (1960) suggested that the upset of the nucleic acid metabolism ultimately results in disturbed protein re-duplication causing chromosome to break at different loci. Evans (1977) pointed out that DNA molecule is responsible for the linear continuity of the chromosomes and the chromosome breakage is due to misrepair of DNA. However, no definite mode of action to chlorinated pesticides can be assigned due to the lack of data.

Generally, the multivalents were observed in all the treatments, though the percentage was low in seed-soak treatments. Quadrivalents-heptavalents in chain, ring or half ring forms were noted in different treatments. Ethyl methane sulfonate (EMS) and methyl methane sulfonate (MMS) - well known mutagens are also known to induce the formation of rings of quadrioctavalents in P. sativum (Narsinghani and Kumar 1971). Such association of chromosomes may be explained due to interlocking of bivalents at meiosis or an accidental entanglement of chromosomes may lead to exchange of chromatids i.e. translocation. In nature the translocation heterozygote may arise due to structural rearrangement of chromosomes in homozygous free mating population. Hence, there is risk that routine pesticides treatmens may give rise to new variants due to interchange of chromosomes. This also suggests that the increasing use of chemicals like pesticides might have played a significant role in elimination and generation of new species i.e. evolution. However, Ghatneker (1964) suggested that multivalents arise due to stickiness.

The frequency of chromatin bridges at ana-telophase-II was lower than at anaphase-I. In seed-soak treatment the chromatin bridges at ana-telophase-II were totally lacking while in spray treatments they were observed only in BHC, Lindane and Heptachlor treatments in low magnitude. In the present investigation the magnitude of anaphase-II bridges never exceeded the magnitude of anaphase-I bridges. This suggests that the bridges of anaphase-II are merely of anaphase-I which survived upto the second division. The presence of anaphase-I bridges along with multivalents at metaphase-I are of great significance from the evolutionary point of view and suggest that translocation and inversion may occur under the influence of pesticides treatments. If by chance these become associated with gene combination they may become established as permanent acquisition of species population, either in the homozygote or hetterozygote form.

Cytomixis was first observed by Gates (1911) in Oenothera gigas and subsequently by other workers (Müntzing and Prakken 1911, Kamara 1960, Sarbhoy 1980). This abnormality was observed only in L. culinaris and L. esculenta due to spray treatment of BHC. The cells showing cytomixis were generally observed at anaphase-I and ana-telophase-II but sometimes also observed at metaphase-I. This process evidently results in the loss or gain of chromatin in some cells. Chromatin loss which is not lethal to the cell may lead to the formation of nuclei with varying chromosomal constitution as is evident by the occassional observance of polyads in $L$. esculenta.

The presence of binucleate cells in L. esculenta suggests that either cytomixis or syndiploidy have taken place or there was fusion of two PMC's followed by mixing of cytoplasm leading to the formation of binucleate pollen mother cell. The binucleate PMC may also develop due to non-disjunction of two daughter nuclei in the germinal cell at the last division before meiosis and the individaul nuclei developed synchronously and passed through various prophase stages upto metaphase-I. The chromosomes originating from the two result in the development of 14 bivalents at metaphase-I as observed in $P$. sativum, although no binucleate cell was detected in the same. The term syndiploidy was first coined out by Strasburger (1907) and Karpechenko (1927) pointed out the role of syndiploidy in production of polyploids in nature. The evolutionary significance of syndiploidy lies in the production of diploid gametes and threrby leading 
to the development of triploids and allotetraploids. Therefore, it is necessary to make routine survey in the fields and locality where the pesticides are applied to evaluate whether the pesticides application is causing lethal genetic damage in plants and living fauna.

The spontaneous chromosomal aberrations and various suggestions regarding their occurrence in nature have been presentaed by various workers. In some cases spontaneous mutations are found to be associated with hybridity (Giles 1940, 1941, Walters 1950). The temperature fluctuation in environment (Husking and Cheng 1950, Nakahara and Komoto 1957) and nutritional defficiencies (Steffensen 1953, 1955) are also known to cause such changes. Sparrow (1950) suggested that spontaneous mutations are not only the result of naturally occurring radiations. The present study clearly reveals that the hereditary constitution of an organism may be changed as a result of pesticides treatments. Such changes occur in nature following the use of pesticides and may have far reaching implications in the maintenance of pure seed lines, resistance of organisms to pesticide and evolutionary change of biota. Furthermore, the present study suggests that long exposure to the pesticides or accumulation of pesticides in the environment as pollutant may cause spontaneous chromosomal anomalies in the domestic animals and human beings also. Therefore, there is great need to make routine survey of different localities to examine the chromosomal behaviour in the plant community in order to ascertain the accumulation of pollutants at particular places. This would prove to be the cheapest and simplest method to detect the intensity of pollution. The greater the spontaneous chromosomal anomalies, the greater would be the accumulation of pollutants at that particular place. Similarly Grant (1978) pointed out that plant chromosomes are sensitive indicators to environmental pollutants and rightly suggested that the higher plants system appears to be an excellent indicator of the cyto-toxic, cytogenetic and mutagenic effects of environmental mutagens. Therefore, the plant system must be accepted as a first tier assay system for detection of the possible genetic damage resulting from the use of environmental chemicals.

\section{C) Effect on the seedling and growth}

In the present investigation a slight fall (3-5\%) in germinability was noticed due to the seed-soak treatment of different pesticides. The fall in seed germination due to the treatment of various pesticides has also been reported by other workers: BHC (Diaz 1954), Aldrin (Bowling 1964) and Endrin (Wuu and Grant 1966). Sevin ( $N$-methyl-1-naphthylcarbamate) is also known to cause marked degree of inhibition of germination in cotton and maize seeds (Amer et al. 1971). The present study reveals that the germinability was effected in different magnitude in different genus. Amer et al. (1971) opined that seeds of different genus show different response to the pesticide treatment.

The seed-soak treatments of various pesticides resulted in delay of epicotyl emergence followed by retardation of shoot growth. The results are in accordance with Brass and Ware (1960), Wurgler et al. (1954) and Fick (1977). The Pisum seeds treated with EMS, X-rays and fast neutrons also showed retardation in seedling height (Narsinghani and Kumar 1971, Chita 1978). Perhaps, the increased mitotic variation, fall in mitotic index and biochemical disturbances are responsible for the retarded growth. Narsinghani and Kumar (1971) noticed marked recovery in seedling height and chromosomal aberrations after $\mathrm{GA}_{3}$ post mutagen treatment. Hence $\mathrm{GA}_{3}$ is effective in reducing phenotypic and genotypic damage to the seedlings. Varner (1964) suggested that $\mathrm{GA}_{3}$ enhances the RNA and protein synthesis which in turn helps to repair the cytological damage caused by physical and chemical mutagens. Hence, the plant growth harmones such as kinetin naturally present in meristematic tissues and dividing cells seems to be responsible for the recovery of affected seedling and chromosomal anomalies during cell division. In all the treatments in $\mathrm{M}_{2}$ generation the mitosis and meiosis (a few cells showed abnormal behaviour of chromosomes) were normal. Therefore, it appears that the cytological 
abnormalities induced by the various pesticides could not persist upto $M_{2}$ generation. Hence, it may be concluded that the pesticide treatment could not affect the gene(s) which control the cell division and various irregularities seem to be due to disturbance in physiological processes.

The plant height in $\mathrm{M}_{1}$ showed a trend of increase in spray treatment of $\mathrm{BHC}$, Aldrin and Heptachlor. In Lindane and Endrin spray treatments the plant height was slightly retarded. Charnetski et al. (1973) also observed retarded growth of $P$. sativum due to Lindane treatment. The difference between $\mathrm{BHC}$ and Lindane treatment seems to be due to the difference in the presence of active agent. In $\mathrm{BHC}$ the growth retarding activity of gamma isomer-Lindane might have been suppressed by the activity of other isomers. A detailed work on the mode of action of other isomers would be necessary to come to a definite conclusion. The maximum increase in height was noticed in the low concentrations. Further increase in concentration of active agent slightly reduced the plant height. The spray treatment of other pesticidesRogor, IPC, Duphar, 2,4-dichlorophenol and 2,4,5-trichlorophenol has been reported to enhance the plant height in cotton (Abd-El-Hamid et al. 1975, 1976).

In $\mathbf{M}_{1}$ generation the number of pods per plant decreased in both the treatments. The more sensitive plant was $L$. esculenta and the least affected plant was $P$. arvense. It suggests that different plants responded differently to the pesticide treatment. The decreased number of pods per plant show that either the flower primordia could not develop or if formed could not reach upto the maturity stage. The number of pods in Vicia faba has also been reported to decrease due to spray and seed-soak treatment of Rogor, IPC and Duphar (Amer and Farah 1976). In $\mathbf{M}_{2}$ generation the number of pods per plant was not affected. Likewise, the yield per plant decreased in $M_{1}$ generation and recovered back to normal in $\mathbf{M}_{2}$ generation.

In $M_{1}$ generation, both spray and seed-soak treatments slightly decreased the pollen viability. Singh et al. (1977) reported that seed-soak treatment by Endrin reduced the pollon viability in barley. The pollen sterility was observed in higher magnitude after spray than seed-soak treatment. It is significant that the ana-telophase-II was little affected or not affected at all, which results in comparatively higher percentage of pollen sterility. Thus, the pollen sterility is not only due to chromosomal aberrations as presumed earlier (Ramanujam and Kumar 1963, Frost and Ising 1963). The pollen sterility is also known to be affected by the persistent and hypertrophied nature of the tapetum (Ohta and Matsumura 1962, Kaul and Singh 1967), formation of large free amino acid pool in the anthers (Patterson et al. 1966). In the present study all the above mentioned factors collectively seem responsible for the pollen sterility. Randawa et al. (1964) also opined that pollen sterility was not always related to meiotic abnormalities.

\section{Summary}

Cytogenetic effects of Benzene hexachloride (BHC), Lindane, Aldrin, Heptachlor and Endrin on Lens culinaris, L. esculenta, Pisum sativum and $P$. arvense were studied through roottip, seed-soak and spray treatments. The probable mechanisms responsible for various type of chromosomal abnormalities and phenotypic alterations due to the treatment of these pesticides have been discussed in detail. Effects of these pesticides did not appear to be heritable in successive generation. But it is difficult to say that these chemicals are entirely safe from genotoxicity point of view. The appearance of multivalents and chromatin bridges suggests that these chemicals can affect genetic recombinations, which may lead to the loss of important factors or gain undesirable characters. The routine cytogenetic screening of standing crops may be one of the helping tool in maintaining the purity of germ plasm. Among all 5 screened chemicals $\mathrm{BHC}$ appeared to be most potent genotoxic agent and suggests to have more detailed mutagenic screening in other test systems also. 


\section{Bibliography}

Abd-El-Hamid, A. M., Amer, S. M. and Ali, E. M. 1975. Effect of some pesticides on cotton plants. Savremena Poljoprivreda 23 (3/4): 99-104.

-, - and Farah, O. R. 1976. Effect of some carbamates on Gossypium barbadense plant. Egypt J. Bot. 19 (2/3): 147-152.

Amer, S. M. and Ali, E. M. 1968. Cytological effects of pesticides III. Meiotic effects of some phenols. Cytologia 33: 21-33.

-, Mostafa, I. Y. and Mikhael, E. 1969. Cytogenetic studies on the effect of chronic gamma irradiation of Vicia faba. Biol. Plant. 11 : 432-41.

-, Hammouda, M. A. and Farah, O. R. 1971. Cytological and morphological effects of insecticide $N$-methyl1-naphthyl carbamate "Sevin". Flora 160: 433-39.

- and Ali, Ennam M. 1974. Cytological effects of pesticides V. Effects of some herbicides on Vicia faba. Cytologia 39: 633-43.

— and Farah O. R. 1976. Cytological effects of pesticides VIII. Effects of the carbamate pesticides "IPC", Rogor and Duphar on Vicia faba. Cytologia 41: 597-606.

Amoore, J. E. 1961a. Arrest of mitosis in roots by oxygen lack or cyanide. Roy. Soc. (London), Proc. B154: 95-108.

- 1961 b. Dependence of mitosis and respiration in roots upon oxygen tension. Roy. Soc. (London), Proc. B154: 109-129.

Baquar, S. R. and Khan, N. R. 1971. Effect of gamma hexa chloro cyclohexane (HCCH) on the mitotic cells of Pisum sativum L. Rev. Biol. 7 (3/4): 195-202.

Berger, C. A., Witkus, E. R, and Sullivan, B. J. 1944. The cytological effects of benzene vapour. Bull. Torrey Bot. Club 71 (6): 620-623.

Bowling, C. C. 1964. Studies on the effects of Aldrin on seed rice germination and emergence. J. Ecol. Entomol. 57 (1): 83-85.

Brass, Charles, L. and Ware, George, W. 1960. BHC translocation from treated soil and the effect on growth of red clover. Econ. Ent.: 110-113.

Bullought, W. S. 1952. The energy relations of mitotic activity. Biol. Rev. 27: 133-168.

Buvat, R. 1963. Electron microscopy of plant protoplasm. Int. Rev. Cytol. 14: 155.

Charnetski, W. A., Lichtenstein, E. P. and Evert, R. F. 1973. Effects of Lindane on cell structure of pea roots. Can. J. Bot. 51 (11): 2111-2117.

Chitu Ovidiu 1978. The relationship between early physiological $M_{1}$ effect and chromosome aberration in Pisum sativum. Trav. Mus. Hist. Nat. Grigore Antipa 19: 55-57.

Cummins, J. E., Bloomquist, J. G. and Rusch, H. P. 1966. Anaphase delay after inhibition of protein synthesis between late prophase and prometaphase. Science 154 (3754): 1343-1344.

D'Amato, F. 1949. Sul l'impiego del gammesano come agente poliploidizzante. Caryologia 1: 209-222.

Datta, N. 1966. Cytological effects of gammexane on somatic chromosomes of Urginea coromandeliana Hook. F. Curr. Sci. 35: 75-76.

Darlington, C. D. 1953. Symposium on chromosome breakage. Heredity 6:1-315.

Diaz, M. D. 1954. Fitotoxicidad de cinco insecticidas aplicados al suelo en la germination $Y$ primer creciemento de cuatro cultivos Acta Agron. (Columbia) 4 (4): 175-202.

Edwards, W. G. H. 1962. Action of some acenaphthene derivatives on mitosis in Pisum roots. Nature 196 (4855): 688-689.

Epel, D. 1963, The effects of carbon monoxide inhibition on ATP level and the rate of mitosis in sea urchin egg, J. Cell Biol. 17: 315-319.

Evans, H. J. 1977. Molecular mechanism in the induction of chromosome aberrations. In: Progress in Genetic Toxicology. D. Scott, B. A. Bridges and F. H. Sobels, Ed. Elseviser/North Holland Biomedical Press, Amsterdam.

Fick, Gary, W. 1977. Methods for evaluating insecticide effects on alfa alfa growth. J. Environ. Qual. 6 (4): $443-445$.

Frey-Wyssling, A. 1938. Submikroskopische Morphologie des Protoplasma und seiner Derivate. Berlin Borntrager.

Frost, S. and Ising, G. 1963 . Cytogenetics of fragment chromosomes in barley, Hereditas 52 (2): 176-180.

Gates, R. R. 1911. Pollen formation in Oenothera gigas. Ann. Bot. 00: 909-40.

Ghatnekar, M. V. 1964. Primary effects of different mutagens and the disturbances induced in meiosis of $\mathrm{X}_{1}$ and $\mathrm{X}_{2}$ of Vicia faba. Caryologia 17: 219-244.

Giles, N. H. 1940. Spontaneous chromosome aberrations in Tradescantia. Genetics 25: 69-87. 
- 1941. Spontaneous chromosome aberrations in triploid Tradescantia hybrids. Genetics 26: 632-649,

Gimenz-Martin, G. and Lopez-saez, J. F. 1962. Accion de la anoxia sobre la mitosis (a-mitosis). Phyton Rev. Internac. Bot. Exptl. Argentina 18 (1): 15-22.

Grant, W. F. 1978. Chromosome aberrations in plants as a monitoring system. Environmental Health Perspectives 27 : $37-43$.

Hoffman-Berling, H. 1954, Die Bedeutung des Adenosintriphosphates für die Zell-und Kernteilungsbewegungen in der Anaphase. Biochim. et Biophys. Acta 15 (2): 226-237.

Hughes, A. 1952. The Mitotic Cycle. Butterworths, London.

Husking, C. L. and Cheng, K. C. 1950. Segregation and reduction in somatic tissues IV. Reductional groupings as induced in Allium cepa by low temperature. J. Heredity 41: 13-18.

Jain, A. K. and Sarbhoy, R. K. 1987. Cytogenetical studies on the effect of some chlorinated pesticides I, II. Cytologia 52: 47-53, 55-61.

Kamara, O. M. P. 1960. Chromatin extrusion and cytomixis in pollen mother cells of Hordeum. Hereditas 46: 592-600.

Karpechenko, G. D. 1927. The production of polyploid gametes in hybrids. Hereditas 9: 349-368.

Kaul, C. L. and Singh, S. P. 1967 . Effects of sodium 2, 3 dichloro iso butyrate sprays on anther development and microsporogenesis of fern-greek (Trigonella foenumgraecium L.). Crop Sci 7: 516-518.

Kihlman, B. A. 1962. The production of chromatid aberrations by 5 -fluorodeoxyuridine alone and in combination with X-rays and 8-ethoxycaffeine. Caryologia 15: 261-277.

Klasterska, I., Natarajan, A. T. and Ramel, C. 1976, An interpretation of the origin of sub chromatid aberrations and chromosome stickiness as a category of chromatid aberrations. Hereditas 83: 153.

Kobayashi, T. 1958. Radiation genetics of sesame I. Meiotic chromosome aberrations induced by absorbed radioactive phosphorous. Jap. J. Genet. 33: 1-11.

Kostoff, D. 1948a. Atypical growth, abnormal mitosis, polyploidy and chromosome fragmentation induced by hexa chloro cyclo hexane. Nature 162: 845-846.

-1948b. Cytogenetic changes and atypical growth induced by hexa chloro cyclo hexane $\left(\mathrm{C}_{8} \mathrm{H}_{6} \mathrm{Cl}_{8}\right)$. Curr. Sci. 17: 294-295.

Kumar, P., Leela, K., Laxminarayan, P. and Nizam, J. 1978. Induction of multipolar spindle in Allium sativum. Cytobios 22: 41-45.

Levan, A. and Östergren, G. 1943. The mechanism of C-mitotic action: Observations on the naphthalene series. Hereditas 29: 381-443.

McGill, M., Pathak, S. and Hsu, T. C. 1974. Effects of ethidium bromide on mitosis and chromosomes A possible material basis for chromosome stickiness, Chromosoma 47: 157.

Mohandas, T. and Grant, W. F. 1972. Cytogenetic effects of 2, 4-D and amitrole in relation to nuclear volume and DNA content in some higher plants. Canad. J. Genet. Cytol. 14: 773-783.

Müntzing, A. and Prakken, R. 1941. Chromosomal aberrations in rye populations. Hereditas 27: 273-308.

Nakahara, K. and Komoto, Y. 1957. The effect of high temperature on the meiotic figures of Tradescantia paludosa, Cytologia 22: 1-11.

Narsinghani, V. G. and Kumar, Sudhir 1971. The effect of gibberellic acid on chromosomal aberrations in EMS and MMS treated Pisum sativum Linn. Theoretical and Applied Genetics 41: 18-20,

Ohta, T. and Matsumura, S. 1962, Cytological observations on chemically induced male sterility in sugar beets. Seiken Ziho 14: 53-60.

Östergren, G. 1944. Colchicine mitosis, chromosome contraction narcosis and protein chain folding. Hereditas 39: 429-467.

Patterson, W. J., Scott, R. A. (Jr.), Carn, H. R. and Heiden, P. A. 1966. The male sterility response in cottonThe effect of 2, 3 dichloro 2-methyl propionate (FW-450) on the incorporation of amino acids in floral tissue. Phyton (B. Aires) 23: 43-48.

Porter, K. R. and Machado, R. D. 1960, Studies on the endoplasmic reticulum IV. Its form and distribution during mitosis in cells of onion root tip. J. Biophys. Biochem. Cytol. 7: 167-180.

Prasad, A. B. 1974. Production of multipolar spindle in canary grass following irradiation of dry seeds. J. Cytol. Genet. 7-8: 184-87.

Quidet, P. and Hitier, H. 1948. Obtention de plantes polyploides par traitement a l'hexa chloro cyclo hexane et au sulfure de polychlorocyclane. C. R. Acad. Sci. 226: 833-835.

Ramanujam, S. and Kumar, S. 1963. Irregular meiosis associated with pollen sterility in Vetivera zyzanioides (Linn.) Nash. Cytologia 28 (3): 242-247.

Randawa, G. S., Yadav, I. S. and Varma, H. S. 1964. A note on cytology of some plums and peach varieties grown under sub-tropical conditions. Ind. J. Hort. $21: 242$.

Sarbhoy, R. K. 1980. Spontaneous occurrence of cytomixis and syndiploidy in Cyamopsis tetragonoloba (L.) 
Taub. Cytologia 45: 375-379.

Sawamura, S. 1965. Cytological studies on the effect of herbicides on plant cells in vivo II. Non harmonic herbicides. Cytologia 30 (3): 325-348.

Sharma, A. K. and Chaudhri, M. 1959. An aspect of gammexane (hexa chloro cyclo hexane) effect on chromosomes. Curr. Sci. 28: 498-499.

- and Sharma, A. 1960. Spontaneous and chemically induced chromosome breaks. Int. Rev. Cytol. 19: 101-136.

- and Sharma, Mandira 1961. A detailed analysis of the control of temperature on gammexane induced polyploidy and different cell injuries. Nucleus 4 (2): 157-168.

- and Chatterji, Asoke Kumar 1962. Chromosome size as a factor in radiosensitivity. Nucleus 5 (1): $67-74$.

- and Talukdar, G. 1965. Effect of gammexane on pollen mother cells of Allium cepa. Biologia Bratislava 20: 105 .

Singh, B. D., Singh, Y., Singh, R. B., Singh, R. M., Sarma, N. D. R. K. and Singh, J. 1977. Cytogenetic aberrations and morphological changes induced by insecticide treatments of barley seeds. Ind. J. Exp. Biol. 15: 688-91.

Sparrow, A. H. 1950. Tolerance of Tradescantia to continuous exposure to gamma radiation from Cobalt 60 . Genetics 35: 135 .

- and Rossenfeld, F. M. 1946. X- ray induced depolymerisation of thymus nucleohistone and of sodium thyonucleate. Science 104: 245-246.

Steffensen, D. 1953. Induction of chromosome breakage at meiosis by a magnesium defficiency in Tradescantia. Proc. Natl. Acad. Sci. 39 : 613-620.

- 1955. Chromosome breakage by a magnesium defficiency in Tradescantia. Proc. Natl. Acad. Sci. 41: $155-160$.

Steinegger, E. and Levan, A. 1947. Constitution and C-mitotic activity of isocolchicine. Hereditas 33: 385396.

Strasburger, E. 1907. Über die Individulität der Chromosomen und die Pfropfhybridenfrage. Jahrb. f Wiss. Bot. 44: 482-556.

Swann, M. M. 1954. The control of cell division. In Recent Developments in Cell Physiology, J. A. Kitching ed., Butterworths (London).

Tanaka, N. and Sugimura, A. 1956. The effect of azaserine on mitotic cells of Tradescantia paludosa with special reference to restoration and protection against the damage caused by azaserine. Proc. Int. Genet. Symp. 1956: 189-195.

Taylor, J. H. 1962. Chromosome reproduction. Int. Rev. Cytol. 13: 39-73.

Tomkins, D. J. and Grant, W. F. 1976. Monitoring natural vegetation for herbicide induced chromosomal aberrations. Mutat. Res. 36: 73-84.

Vaarama, A. 1947. Experimental studies on the influence of DDT insecticide upon plant mitosis. Hereditas 33: $191-219$.

Varner, J. E. 1964. Gibberellic acid controlled synthesis of $\alpha$-amylase in barley endosperm, Plant Physiol. 39: $413-415$.

Walters, M. S. 1950 . Spontaneous breakage and reunion of meiotic chromosomes in the hybrid Bromus trinei $\times$ B. maritimus. Genetics 35: 11-37.

Wassermann, F. 1929. Wachstum und Vermehrung der lebendigen Masse. In Handbuch der mickroskopischen Anatomie des Menschen. Berlin, Springer.

Whalley, W. C., Mollenhauer, H. H. and Leech, J. H. 1960. The ultrastructure of the meristematic cell. Amer. J. Bot. 47: 401-419.

- and Mollenhauer, H. H. 1963. The Golgi apparatus and cell plate formation. J. Cell Biol. 17: $216-221$.

Wurgler, W., Marc, S. H. and Adrien Bolay 1954. Researches sur la phytotoxicité de 1 hexa chloro cyclo hexane (HCH). Ann. Aggric. Suisse 55: 975-986.

Wuu, K. D. and Grant, W. F. 1966. Morphological and somatic chromosomal aberrations induced by pesticides in barley (Hordeum vulgare). Canad. J. Genet. Cytol. 8: 481-501.

Yakar, N. 1952. Mitotic disturbances caused by Chloranil. Amer. J. Bot. 39: 540. 